\title{
Electron Transfer Reaction from Glucose Oxidase to an Electrode via Redox Copolymers
}

\author{
Takahiro SAITO and Masayoshi WATANABE ${ }^{\dagger}$ \\ Department of Chemistry \& Biotechnology, Yokohama National University, \\ 79-5 Tokiwadai, Hodogaya-ku, Yokohama 240-8501, Japan
}

(Received February 12, 1999)

\begin{abstract}
This study has aimed at exploring the relationship between redox polymer structures and the electron transfer reaction from glucose oxidase (GOx) to an electrode via the redox polymers. Two series of flexible redox copolymers; poly[vinylferrocene- $c o-\alpha$-methacryloyl- $\omega$-methoxy-oligo(ethylene oxide)] (VFc-MEO) and poly(vinylferrocene-co-dodecyl methacrylate) (VFc-MD), were prepared, where VFc and MD are hydrophobic monomers, while MEO is a hydrophilic monomer. These redox copolymers were utilized as electron mediators for the enzymatic reaction of GOx in carbon paste electrodes. Both of the flexible VFc-MEO and VFc-MD copolymers were found to function as polymeric mediators for the electron transfer reaction between GOx and the electrode, while the catalytic current responses were completely different depending on the structure of the polymeric mediators. The magnitude of the catalytic current of the VFc-MEO electrodes was larger than that of the VFc-MD electrodes at any VFc composition in the copolymers. At a constant glucose concentration, the catalytic current of the VFc-MEO electrodes passed through a maximum with increasing the VFc composition in the copolymers, whereas that of the VFc-MD electrodes monotonously increased with increasing the VFc composition. These differences in the electron transfer reaction have been explained in terms of the difference in amphiphilicity of the copolymers.
\end{abstract}

KEY WORDS Electron Transfer Reaction / Glucose Oxidase / Redox Polymer / Mediator / Ferrocene /

In the field of amperometric glucose electrodes based on the enzymatic reaction of glucose oxidase (GOx), many redox active species have been utilized as electron mediators between GOx and an electrode. For conventional glucose electrodes, monomeric redox species, such as ferrocene and quinone derivatives, have been used as the mediator molecules. ${ }^{1-5}$ Recently, however, certain redox polymers, such as ferrocene-modified-polysiloxane, ${ }^{6}$ ferrocenemodified-poly(acrylamide-co-acrylic acid), ${ }^{7}$ ferrocenemodified-polyallylamine, ${ }^{8}$ poly(N-isopropylacrylamide-covinylferrocene), ${ }^{9}$ poly(acrylamide-co-vinylferrocene) $),{ }^{10,11}$ and macromolecular osmium bipyridine complexes, ${ }^{12,13}$ were found to function as polymeric mediators in the glucose electrodes. When a monomeric mediator is used, the charge transport from the redox center of GOx (reduced form of flavin adenine dinucleotide: $\mathrm{FADH}_{2}$ ) to an electrode is conducted by free diffusion of the mediator. In other words, the oxidized form of monomeric mediators approaches the active sites of GOx and accepts electrons from $\mathrm{FADH}_{2}$, and then the resulting reduced form of the mediators diffuses toward an electrode to give electrons. The charge transport rate between GOx and an electrode is, thus, dominated by the charge transfer rate constant between $\mathrm{FADH}_{2}$ in $\mathrm{GOx}$ and the mediator, and its diffusivity. On the contrary, in a polymeric mediator system, since the redox active sites are covalently attached to the polymer backbone, free diffusion of the redox sites is impossible. For the electron transport from $\mathrm{FADH}_{2}$ to an electrode, electron must be transferred by electron hopping reaction in the redox polymers. ${ }^{14}$ The electron hopping rate is enhanced with increasing the electron-self-exchange rate constant and concentration of the redox centers, and flexibility of the polymers. ${ }^{14-16}$ These variables may also affect the electron transfer from $\mathrm{FADH}_{2}$ to the oxidized form of the redox centers. However, what are the critical requirements for the redox polymers to function effectively as a polymeric mediator in the enzyme electrodes is still not clear at the present, since most of the previous

\footnotetext{
${ }^{\dagger}$ To whom correspondence should be addressed.
}

studies aimed their target at their application and at the optimization of the sensor response.

In addition to the fundamental interest to understand the electron transfer reaction from GOx to an electrode, to use redox polymers in the glucose electrodes may afford the long term stability and the easy fabrication. In the glucose electrodes using monomeric mediators, the mediators frequently diffuse out from the electrodes into analytes for the long term operation. Toxicity of the mediator molecules limits their applicability to in vitro use. The polymeric mediators may also have the capability to immobilize GOx as biocompatible electrodes ${ }^{17}$ and as selective membranes to exclude interfering substances in body fluids. ${ }^{11}$

In this study, two series of redox copolymers (Figure 1); poly [vinylferrocene-co- $\alpha$-methacryloyl- $\omega$-methoxyoligo(ethylene oxide)] (VFc-MEO) and poly(vinylferroceneco-dodecyl methacrylate) (VFc-MD), with several compositions, were prepared in order to explore the relationship between the redox polymer structures and the electron transfer reaction from GOx to an electrode via the redox polymers in carbon paste electrodes. VFc was used as a redox monomer, since its monomer analogues ${ }^{1}$ and its copolymers $^{9-11}$ have been demonstrated to function as effective mediators for the electron transfer reaction of GOx. As the comonomers of VFc, hydrophilic MEO and
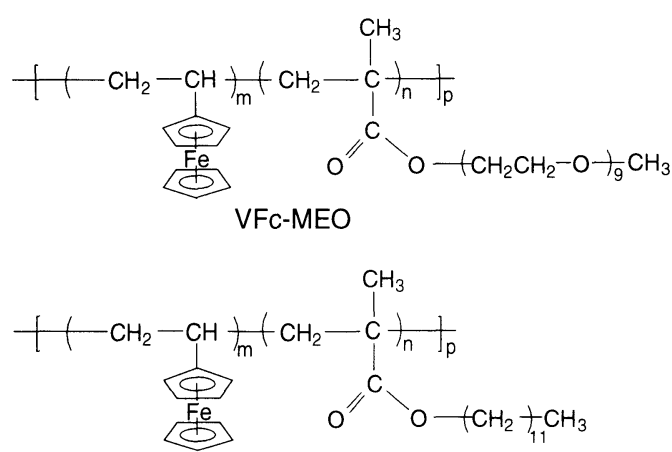

VFc-MD

Figure 1. Structure of redox copolymers. 
hydrophobic MD were selected. Both of VFc-MEO and VFc-MD were expected to give flexible copolymers, and the redox site concentration and the amphiphilicity were controllable, depending on the comonomer structure and on the copolymer composition.

\section{EXPERIMENTAL}

\section{Materials}

Vinylferrocene was synthesized according to a conventional method ${ }^{18,19}$ and purified by sublimation. Its purity was identified by ${ }^{1} \mathrm{H}$-NMR. $\alpha$-Methacryloyl$\omega$-methoxy-oligo(ethylene oxide) (MEO, Polyscience, nominal average mol. wt. $=470)$ were used as received. Polymerization inhibitor in dodecyl methacrylate (MD, Junsei Chemical) was removed by using inhibitor remover columns (Aldrich). 2, 2'-Azobis(isobutyronitrile) (AIBN, Wako Pure Chemical) was recrystallized three times from methanol below $35{ }^{\circ} \mathrm{C}$. Benzene used for the copolymerization was repeatedly washed with sulfuric acid, then washed with an aqueous sodium hydroxide solution and water, successively, dried over calcium chloride, and purified by fractional distillation. The other chemicals were reagent grade and used without further purification.

\section{Copolymer Preparation and Characterization}

The VFc-MEO and VFc-MD copolymers, with several compositions, were prepared by radical copolymerization. Into a glass ampule were injected a mixture of VFc and the comonomer (either MEO or MD) at a known ratio, AIBN ( $0.5 \mathrm{~mol} \%$ on the basis of total monomers) as a radical initiator, and benzene (the monomer concentration was the same for all the samples, $5 \mathrm{~mol} / \mathrm{dm}^{3}$ ). The ampule was evacuated by freeze-thaw cycles and sealed under vacuum. The polymerization was conducted at $60{ }^{\circ} \mathrm{C}$. The copolymers were purified by repeated reprecipitation from a benzene solution into an excess of diethyl ether and dried under vacuum. The copolymer composition was determined by the maximum absorbance (Shimadzu UV160A) at ca. $440 \mathrm{~nm}$, assignable to ferrocenyl group. Ferrocene $\left(\lambda_{\max }=440 \mathrm{~nm}\right)$ was used as a standard substance for the composition determination. Gel permeation chromatography (GPC) was carried out with Shodex GPC KF-806L columns (two columns connected in series) using tetrahydrofuran as the elution solvent at a flow rate of 1 $\mathrm{ml} / \mathrm{min}$ driven by a Shimadzu LC-10AD pump. Chromatographs were recorded by using a UV-Vis detector (Shimadzu SPD-10AV). The columns were calibrated with narrow distribution polystyrene standards (Showa Denko) by using the UV-Vis detector. Glass transition temperature $(\mathrm{g})$ of the copolymers was determined by using a differential scanning calorimeter (Seiko Instruments DSC200) at a heating rate of $10{ }^{\circ} \mathrm{C} / \mathrm{min}$.

\section{Preparation of Carbon Paste Electrodes and \\ Electrochemical Measurements}

Carbon paste electrodes were used for convenience to explore the electron transfer reaction between GOx and an electrode via the redox copolymers. GOx (Toyobo, EC 1.1.3.4, Lot No. 42550) and the redox polymer were added to carbon paste based on graphite particles, sufficiently mixed together, and packed into a cylindrical carbon paste electrode (BAS, $3 \mathrm{~mm}$ inner diameter) to prepare the electrodes. The weight ratio of GOx : redox copolymer : carbon paste was fixed in this study at $5: 3: 40$. Analyte solutions were prepared by dissolving D-glucose (Junsei Chemical) in a phosphate buffer solution ( $\mathrm{pH}$ 7.4) at several concentrations. The solutions were allowed to stand for 2 days in order to reach the equilibrium between the $\alpha$ - and $\beta$-forms. Before electrochemical measurements, the analyte solutions were thoroughly deoxygenated by $\mathrm{N}_{2}$-bubbling for at least $10 \mathrm{~min}$. Cyclic voltammetry and constant potential measurements were carried out at room temperature with an electrochemical work station (BAS 100BW) in a Faraday cage, by using a

Table I. Polymerization and characterization of VFc-MEO

\begin{tabular}{|c|c|c|c|c|c|c|c|c|}
\hline \multirow{2}{*}{ Abbreviation } & \multicolumn{2}{|c|}{ Polymerization Condition ${ }^{\mathrm{a}}$} & \multicolumn{5}{|c|}{ Polymer Characterization } & \multirow[b]{2}{*}{$\operatorname{Tg} /{ }^{\circ} \mathrm{C}^{\mathrm{d}}$} \\
\hline & $\begin{array}{c}\text { VFc mole fraction } \\
\text { in feed }\end{array}$ & Time/ h & Conversion (\%) & $\begin{array}{l}\text { VFc mole fraction } \\
\text { in copolymer }\end{array}$ & $M \mathrm{n}^{\mathrm{c}}$ & $M \mathrm{w}^{\mathrm{c}}$ & $M \mathrm{w} / M \mathrm{n}^{\mathrm{c}}$ & \\
\hline VFc-MEO(20) & 0.13 & 5.5 & 39 & 0.20 & $-\mathrm{e}$ & $-\mathrm{e}$ & $-\mathrm{e}$ & -60 \\
\hline VFc-MEO(41) & 0.32 & 50 & 40 & 0.41 & 17400 & 21300 & 1.23 & -58 \\
\hline VFc-MEO(56) & 0.58 & 250 & 21 & 0.56 & 23700 & 41900 & 1.77 & -57 \\
\hline VFc-MEO(70) & 0.83 & 300 & 17 & 0.70 & 13500 & 19500 & 1.44 & -54 \\
\hline
\end{tabular}

Table II. Polymerization and characterization of VFc-MD

\begin{tabular}{|c|c|c|c|c|c|c|c|c|}
\hline \multirow[b]{2}{*}{ Abbreviation } & \multicolumn{2}{|c|}{ Polymerization Condition ${ }^{a}$} & \multicolumn{5}{|c|}{ Polymer Characterization } & \multirow[b]{2}{*}{$T \mathrm{~g} /{ }^{\circ} \mathrm{C}^{\mathrm{d}}$} \\
\hline & $\begin{array}{c}\text { VFc mole fraction } \\
\text { in feed }\end{array}$ & Time/ h & Conversion (\%) & $\begin{array}{l}\text { VFc mole fraction } \\
\text { in copolymer }\end{array}$ & $M \mathrm{n}^{\mathrm{c}}$ & $M \mathrm{w}^{\mathrm{c}}$ & $M \mathrm{w} / M \mathrm{n}^{\mathrm{c}}$ & \\
\hline VFc-MD(19) & 0.13 & 10 & 63 & 0.19 & 61500 & 114000 & 1.85 & -54 \\
\hline VFc-MD(47) & 0.40 & 53 & 67 & 0.47 & 31900 & 57300 & 1.80 & -32 \\
\hline VFc-MD(68) & 0.60 & 150 & 55 & 0.68 & 15300 & 29700 & 1.94 & -27 \\
\hline VFc-MD(93) & 0.80 & 300 & 45 & 0.93 & 7500 & 14600 & 1.95 & -23 \\
\hline
\end{tabular}

${ }^{\text {a }}$ Polymerization was done at monomer concentration of $5 \mathrm{~mol} / \mathrm{dm}^{3}$ at $60{ }^{\circ} \mathrm{C}$ in the presence of $0.5 \mathrm{~mol} \%$ of $\mathrm{AIBN}$.

${ }^{\mathrm{b}}$ Determined from the absorbance at $440 \mathrm{~nm}$ based on the adsorption of ferrocenyl group.

${ }^{\mathrm{c}}$ Determined from GPC (UV-Vis detector ; $250 \mathrm{~nm}$ ) calibrated by polystyrene standards.

d Determined from DSC.

e No GPC data because of partial gelation. 
carbon paste electrode as a working electrode, a platinum wire as a counter electrode, and a saturated calomel electrode (SCE) as a reference electrode. Before electrochemical measurements, the electrodes were immersed in a phosphate buffer solution ( $\mathrm{pH} 7.4$ ), and the stable response was confirmed by using cyclic voltammetry.

\section{RESULTS AND DISCUSSION}

\section{Characterization of Redox Copolymers}

Tables I and II summarize the results of preparation and characterization of the VFc-MEO and VFc-MD copolymers, respectively. Radical polymerizability of VFc toward these methacrylate comonomers was rather poor, as indicated by the decreases in the copolymerization rate and in the molecular weight with increasing the VFc fraction in the feed (Tables I and II). However, the VFc-MEO and VFc-MD copolymers, with several VFc compositions, could be obtained by using the polymerization conditions shown in Tables I and II. The copolymer composition curves for

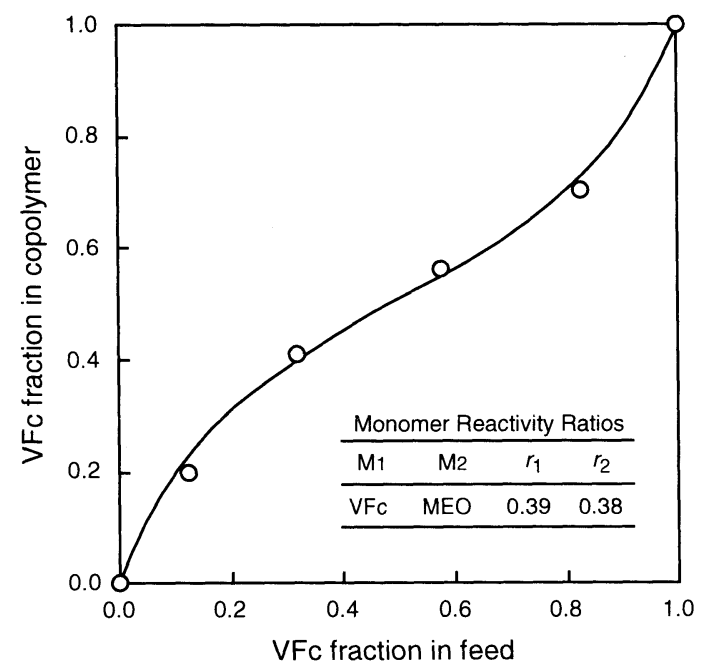

Figure 2. Copolymer composition curve for VFc-MEO copolymers.

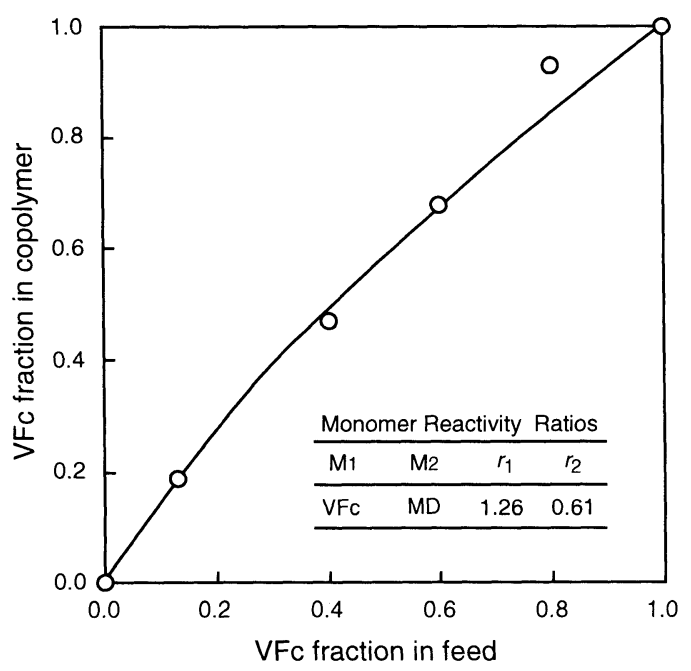

Figure 3. Copolymer composition curve for VFc-MD copolymers.
VFc-MEO and VFc-MD are shown in Figures 2 and 3, respectively. The monomer reactivity ratios determined by Kelen-Tüdôs method ${ }^{20}$ are shown in the insets of Figures 2 and 3. The copolymer composition curves in Figures 2 and 3 are calculated curves by using the $r_{1}$ and $r_{2}$ data.

Both of the VFc-MEO and VF-MD copolymers obtained were orange-colored rubbery materials, reflecting their $T g^{\prime} \mathrm{s}$ lower than room temperature (Tables I and II). $T g^{\prime}$ 's of the VFc-MEO copolymers range from $-60{ }^{\circ} \mathrm{C}$ to $-54{ }^{\circ} \mathrm{C}$ and do not greatly depend on the VFc composition, whereas those of the VFc-MD copolymers range from $-54{ }^{\circ} \mathrm{C}$ to $-23{ }^{\circ} \mathrm{C}$ and increase with increasing the $\mathrm{VFc}$ composition. In terms of amphiphilicity of the copolymers, VFc-MEO and VFc-MD were completely different. The equilibrium water uptake under $100 \%$ relative humidity at $20{ }^{\circ} \mathrm{C}$ for VFc-MEO decreased from $44 \mathrm{wt} \%$ to $28 \mathrm{wt} \%$ with increasing the VFc composition. On the other hand the water uptake for VFcMD was negligible irrespective of the composition.

\section{Mediation of Electron Transfer Reaction by Redox Polymers}

Figure 4 shows cyclic voltammograms of the carbon paste electrodes containing either VFc-MEO(70) or VFc-MD(93) in the phosphate buffer solutions with or without dissolved glucose, as typical examples. In the absence of glucose (broken lines), both of the voltammograms exhibit anodic and cathodic current peaks. These redox waves can be assigned to the oxidation and reduction of ferrocenyl group in the copolymers, which indicates redox activity of the both of the copolymers in the electrodes. The diffusioncontrolled redox response is caused by the electron hopping between the adjacent ferrocenyl groups in the copolymers as the charge transport mechanism. Although both of the copolymers are redox active, there are large differences between the responses of the VFc-MEO and VFc-MD electrodes. The magnitude of current for the VFc-MEO electrode is about 70 times as large as that for the VFc-MD electrode in the buffer solution. We consider that this result is related to the differences in ionic conductivity and hydrophilicity between the VFc-MEO and VFc-MD copolymers. It is well known that poly(ethylene oxide) and related polymers are ion-conducting polymers which form polymer electrolytes when complexed with ionic species. ${ }^{21}$ Solid state voltammetry becomes possible by using the ionconducting polymers as polymeric solvents for electroactive solutes. $^{22,23}$ It is also demonstrated by our group that the VFc-MEO copolymers, where the electroactive cites are covalently attached to the polymer backbone, are redox active by themselves even in the absence of fluid solvents. ${ }^{16}$ Furthermore, because of the hydrophilicity of VFc-MEO, the ionic conductivity must be enhanced by the water sorption. Judging from these results, the redox reaction of the VFcMEO electrode, shown in Figure 4, occurs not only at the electrode surface in contact with the buffer solution but also at inner part of the electrode. Large peak separation seen in the voltammogram may be caused by the large redox current. On the other hand, the VFc-MD copolymers are neither polar nor hydrophilic. The bulk ionic conductivity of the copolymers should be extremely low. It is likely that the redox reaction of the VFc-MD electrode, shown in Figure 4, occurs only in the vicinity of the carbon paste electrode surface in contact with the buffer solution. The total amounts of redox sites that can be oxidized and reduced during the voltammetric cycle are completely different 
between the VFc-MEO and VFc-MD electrodes, even when the composition of the carbon paste electrodes is the same. These results cause the differences in the current response between the VFc-MEO and VFc-MD electrodes in the buffer solution.

In the presence of glucose (Figure 4, solid lines), the oxidation current increases at the potential range where the oxidation of ferrocenyl sites in the copolymers proceeds, for both of the VFc-MEO and VFc-MD electrodes whereas the reduction current decreases. When the electrodes are in contact with glucose solutions, the enzymatic reaction of GOx proceeds within the electrodes. By this enzymatic reaction, the co-enzyme $\mathrm{FAD}$ is converted to $\mathrm{FADH}_{2}$. Polarization of the electrode potential higher than the redox potential of ferrocenyl group in the copolymers generates ferrocenium ion, which extends from the surface of graphite particles in the carbon paste electrode to the bulk polymeric phase by electron hopping reaction and reaches the vicinity of $\mathrm{FAD} / \mathrm{FADH}_{2}$ in GOx. Since the redox potential of $\mathrm{FAD} / \mathrm{FADH}_{2}(-0.46 \mathrm{~V}$ vs. SCE) is much lower than that of ferrocene/ferrocenium couple ( $c a .0 .3 \mathrm{~V}$ vs. SCE), the propagated ferrocenium sites oxidize $\mathrm{FADH}_{2}$ to FAD. By this oxidation reaction, ferrocenium sites in the copolymers are reduced to original ferrocene sites. These reactions catalytically cycle and are responsible for the enhancement of the oxidation current in the presence of glucose. The

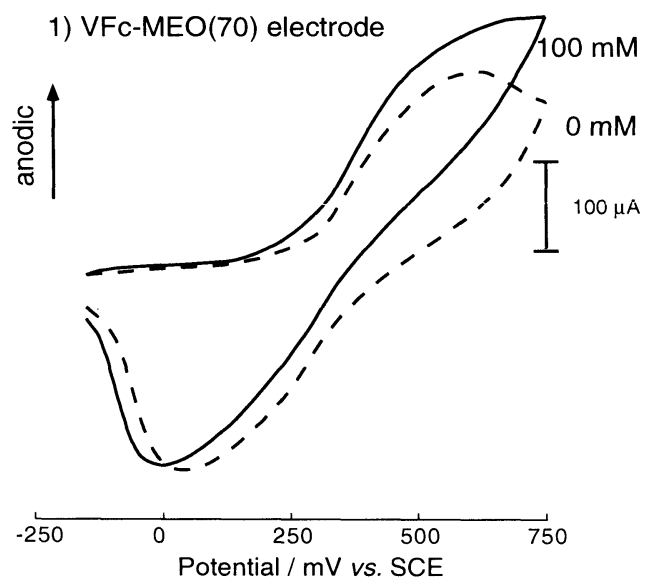

2) VFc-MD(93) electrode

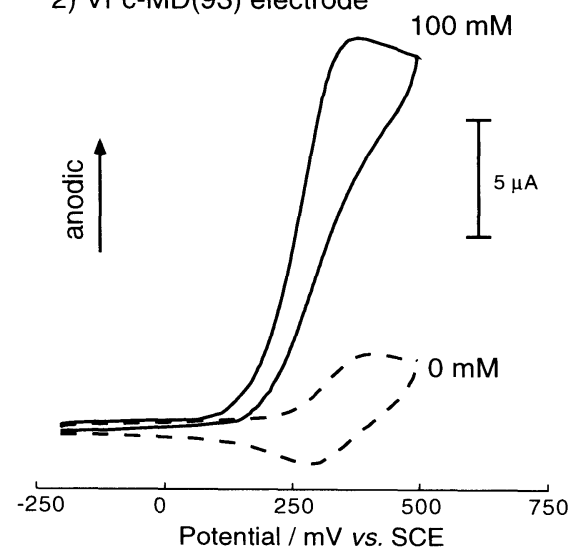

Figure 4. Cyclic voltammograms of carbon paste electrode in the absence and presence of glucose in phosphate buffer solutions ( $\mathrm{pH}$ 7.4) at scan rate of $5 \mathrm{mV} / \mathrm{s}$. enhancement of oxidation current clearly demonstrates that the highly flexible VFc-MEO and VFc-MD copolymers incorporated in the carbon paste electrodes function as electron mediators between $\mathrm{FADH}_{2}$ and the electrode, irrespective of the hydrophilicity and hydrophobicity of the copolymers.

The ratios of the catalytic current $\left(i_{\text {cal }}\right)$ to the current in the absence glucose $\left(i_{\text {redox }}\right)$ for the both electrodes are greatly different (Figure 4). Although $i_{\text {cat }}$ of the VFc-MEO electrode is larger than $i_{\text {cat }}$ of the VFc-MD electrode, $i_{\text {cat }} / i_{\text {redox }}$ of the latter is much larger than that of the former. Furthermore, the reduction current of the VFc-MD electrode in the presence of glucose is not seen, whereas that of the VFc-MEO electrode still remains. The oxidation reaction of ferrocene sites in the VFc-MEO electrode occurs at each interface between graphite particles and the copolymer inside the carbon paste electrode because of its high ionic conductivity $^{16}$ (vide supra). In the anodic scan, many ferrocenium sites are formed in the carbon paste electrode. However, only a part of the ferrocenium sites can participate in the mediation reaction, since the enzymatic reaction of GOx occurs only in the vicinity of the electrode surface, where glucose can diffuse from the solutions. This is a reason for the low $i_{\text {cat }} / i_{\text {redox }}$ ratio for the VFc-MEO electrode. In the cathodic scan, most of the ferrocenium sites are reduced by the electrode reaction, and the reduction current is still observed at the VFc-MEO electrode. On the other hand, the ferrocenium sites in the VFc-MD electrode are generated only at the surface of the electrode, and most of the ferrocenium sites, generated in the oxidation process, are chemically reduced by $\mathrm{FADH}_{2}$ produced by the enzymatic reaction of GOx. For this reason the catalytic efficiency is high, and the reduction current is not observed for the VFcMD electrode.

\section{Redox Copolymer Structure and Catalytic Current}

Figures 5 and 6 show steady-state catalytic current at $+0.35 \mathrm{~V}$ vs. SCE as a function of glucose concentration for the carbon paste electrodes containing the VFc-MEO and VFc-MD copolymers with different compositions, respectively. For the VFc-MD electrodes, the catalytic current reaches a steady-state value within $60 \mathrm{~s}$ after applying the potential, whereas it took about $10 \mathrm{~min}$ to reach it for the VFc-MEO electrodes. The steady-state catalytic current increases with increasing of the glucose concentration and tends to saturate at the higher glucose concentrations for both of the electrodes. It is likely that this behavior follows the Michaelis-Menten kinetics, as is seen in many amperometric enzyme electrodes. The apparent Michaelis-Menten constant $K_{\mathrm{tn}}^{\text {app }}$ can be determined from the electrochemical Eadie-Hofstee form of the Michaelis-Menten equation: ${ }^{24}$

$$
j_{\mathrm{ss}}=j_{\max }-K_{\mathrm{m}}{ }^{\mathrm{app}}\left(j_{\mathrm{ss}} / C^{\prime}\right)
$$

where $j_{\mathrm{ss}}$ is steady-state catalytic current, $j_{\max }$ is the maximum catalytic current under saturated substrate conditions, and $C$ is substrate concentration, glucose concentration in this case. The results of this Michaelis-Menten analysis are summarized in Table III. The solid lines in Figures 5 and 6 are calculated lines by using the $K_{\mathrm{m}}^{\text {app }}$ and $j_{\max }$ values in Table III and the Michaelis-Menten equation, and well reproduce the experimental results.

It is interesting to note that the magnitude of the catalytic 


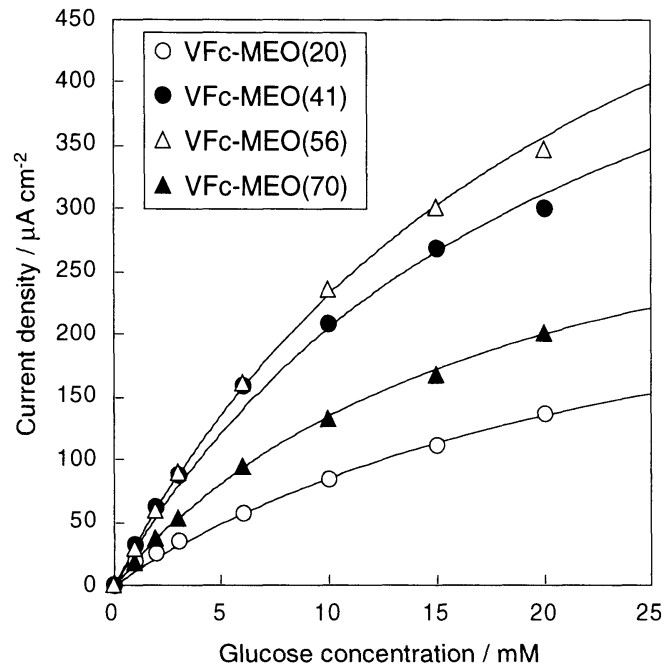

Figure 5. Catalytic current for carbon paste electrodes containing VFcMEO copolymers as a function of glucose concentration. The current was measured at $+0.35 \mathrm{~V} v s$. SCE at $780 \mathrm{~s}$ after applying the potential..

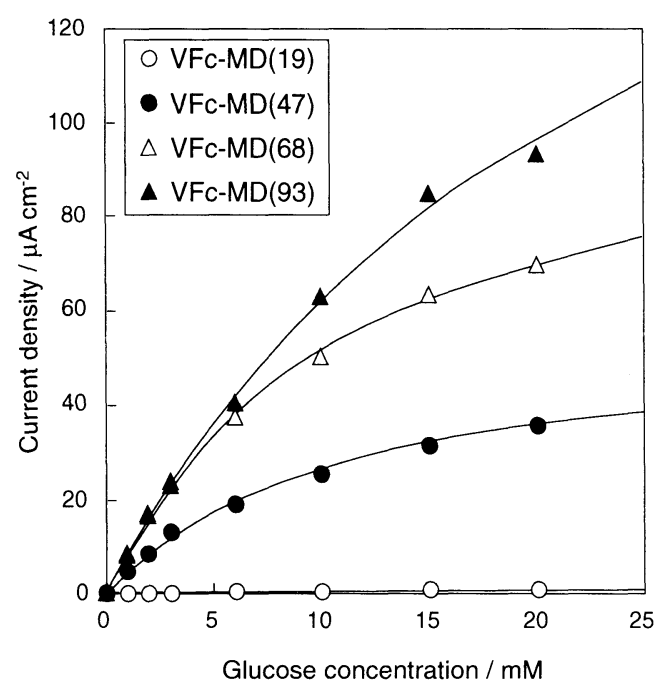

Figure 6. Catalytic current for carbon paste electrodes containing VFcMD copolymers. The current was measured at $+0.35 \mathrm{~V} v \mathrm{~s}$. SCE at 240 $\mathrm{s}$ after applying the potential.

Table III. Apparent Michaelis constants and maximum current densities for VFc-MEO and VFc-MD electrodes

\begin{tabular}{|c|c|c|}
\hline Mediator & $K_{\mathrm{m}}^{\mathrm{app} / \mathrm{mM}}$ & $j \max / \mu \mathrm{Acm}^{-2}$ \\
\hline VFc-MEO(20) & 28.4 & 328 \\
\hline VFc-MEO(41) & 21.7 & 649 \\
\hline VFc-MEO(56) & 23.2 & 770 \\
\hline VFc-MEO(70) & 18.9 & 380 \\
\hline VFc-MD(19) & 11.9 & 1.7 \\
\hline VFc-MD(47) & 11.1 & 56.4 \\
\hline VFc-MD(68) & 10.9 & 108 \\
\hline VFc-MD(93) & 25.0 & 218 \\
\hline
\end{tabular}

current at a given glucose concentration is greatly different, depending on the structure of the copolymers in the electrodes. This is typically shown in Figure 7, where the catalytic current at $20 \mathrm{mM}$ glucose is plotted against the VFc

Polym. J., Vol. 31, No. 11-2, 1999

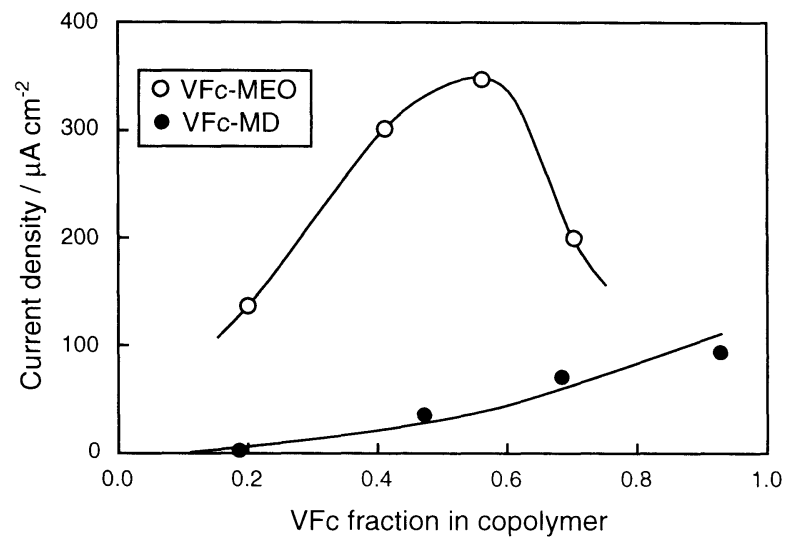

Figure 7. Catalytic current at $+0.35 \mathrm{~V}$ ws. SCE in $20 \mathrm{mM}$ glucose solutions as a function of VFc composition in copolymers.

fraction in the copolymers. The catalytic current of the VFc-MEO electrodes is larger than that of the VFc-MD electrodes, irrespective of the VFc composition. For the catalytic reaction to be electrochemically detected, the partition layer of glucose and diffusion layer of electrochemically generated ferrocenium sites in the copolymers should encounter together in the carbon past electrodes. As the result, the electron transfer reaction from $\mathrm{FADH}_{2}$ to the ferrocenium sites and the electron hopping reaction between the ferrocene/ferrocenium sites should follow. The larger catalytic current of the VFc-MEO electrodes than that of the VFc-MD electrodes seems to be caused by the larger glucose partition into the electrodes due to its hydrophilicity and further the larger amount of electrochemically generated ferrocenium sites (vide supra).

The change in the catalytic current as a function of the VFc composition is also different, depending on the structure of the mediator copolymers (Figure 7). The current for the VFc-MEO electrodes passes through a maximum at the VFc mole fraction of 0.56 , whereas the current for the VFc-MD electrodes monotonously increases with increasing the VFc composition. With increasing the VFc composition in the redox copolymers, the local concentration of the oxidized form in the vicinity of the active center of GOx increases under the steady-state potentiostatic condition. This increase facilitates the electron transfer from $\mathrm{FADH}_{2}$ to the oxidized form. Consequently, the catalytic current increases with increasing the VFc composition. This may be the case for the VFc-MD electrodes, where the copolymers are hydrophobic independent of the composition. In contrast, the VFc-MEO copolymers are amphiphilic copolymers, consisting of hydrophobic VFc and hydrophilic MEO. The increase in the VFc composition causes not only to facilitate the electron transfer from $\mathrm{FADH}_{2}$ to the oxidized form but also to increase in the hydrophobicity of the copolymers, resulting in the decrease in the amount of glucose partitioned into the electrodes. The catalytic current maxima as a function of redox monomer composition have been observed in the GOx carbon paste electrodes containing copolymer mediators consisting of a hydrophobic redox monomer and a hydrophilic monomer, such as poly[ferrocenylmethyl methacrylate-co- $\alpha$-methacryloyl$\omega$-methoxy-oligo(ethylene oxide) $]^{25}$ and poly[vinylferrocene-co-2-hydroxyethyl methacrylate] ${ }^{26}$ 


\section{CONCLUSION REMARKS}

Two series of flexible redox copolymers; poly[vinylferrocene-co- $\alpha$-methacryloyl- $\omega$-methoxyoligo(ethylene oxide)] (VFc-MEO) and poly(vinyl ferrocene-co-dodecyl methacrylate) (VFc-MD), have been prepared by radical copolymerization. Since VFc and MD are hydrophobic monomers, and MEO is a hydrophilic monomer, the VFc-MD copolymers are hydrophobic, independent of their composition, whereas hydrophilicity of the VFc-MEO copolymers decreases with increasing the $\mathrm{VFc}$ composition. Both of the copolymers show redox activity in the carbon paste GOx electrodes and function as electron mediators from GOx to the electrode for the catalytic oxidation of glucose. The mediation reaction occurs irrespective of the amphiphilicity of the flexible copolymers. However, amperometric responses of the electrodes toward glucose are completely different, depending on structure of the mediator copolymers. The magnitude of the catalytic current response is much larger, but the response time is much longer for the VFc-MEO electrodes, when compared with those for the VFc-MD electrodes. The catalytic current of the VFc-MEO electrodes at a constant glucose concentration passes through a maximum with increasing the $\mathrm{VFc}$ composition. In contrast, the current of the VFc-MD electrodes monotonously increases with increasing the $\mathrm{VFc}$ composition.

Acknowledgment. This research was supported in part by Grant-in-Aid for Scientific Research on Priority Areas "New Polymers and Their Nano-Organized Systems" (No. 277/08246220, No. 277/09232222, and No. 277/10126220) from the Japanese Ministry of Education, Science, Sports and Culture.

\section{REFERENCES}

1. A. E. G. Cass, G. Advise, G. D. Francis, H. A. O. Hill, W. J. Aston, I. J. Higgins, E. V. Plotkin, L. D. L. Scott, and A. P. F. Turner, Anal. Chem., 56, 667 (1984).
2. M. J. Green and H. A. O. Hill, J. Chem. Soc. Faraday Trans., 82 , 1237 (1986)

3. J. J. Kulys and N. K. Cenas, Biochim. Biophys. Acta, 744, 57 (1983).

4. C. Bourdillon, C. Demaille, J. Moiroux, and J-M. Savéant, J. Am. Chem. Soc., 115, 2 (1993).

5. I. Rosen-Margalit, A. Bettelheim, and J. Rishpon, Anal. Chim. Acta, 281, 327 (1993).

6. P. D. Hale, T. Inagaki, H. I. Karan, Y. Okamoto, and T. A. Sk otheim, J. Am. Chem. Soc., 111, 3482 (1989).

7. E. J. Calvo, C. Danilowicz, and L. Diaz, J. Chem. Soc. Faraday Trans., 89, 377 (1993).

8. E. J. Calvo, C. Danilowicz, and L. Diaz, J. Electroanal. Chem., 369, 279 (1994).

9. T. Tatuma, K. Saito, and N. Oyama, Anal. Chem., 66, 1002 (1994).

10. H.-Z. Bu, S. R. Mikkelsen, and A. M. English, Anal. Chem., 67, 4071 (1995).

11. H.-Z. Bu, A. M. English, and S. R. Mikkelsen, Anal. Chem., 68, 3951 (1996).

12. Y. Degani and A. Heller, J. Am. Chem. Soc., 111, 2357 (1989).

13. T. J. Ohara, R. Rajagopalan, and A. Heller, Anal. Chem., 65, 3512 (1993).

14. G. Inzelt, "Electroanalytical Chemistry", vol. 18, A. J. Bard, Ed., Marcel Dekker, New York, 1996, pp 89-241; R. W. Murray, Ed., "Techniques of Chemistry vol. 22, Molecular Design of Electrode Surfaces", John Willy, New York, 1992.

15. D. N. Blauch and J-M. Savéant, J. Am. Chem. Soc., 114, 3323 (1992).

16. M. Watanabe, H. Nagasaka, K. Sanui, N. Ogata, and R. W. Murray, Electrochim. Acta., 37, 1521 (1992); M. Watanabe, H. Nagasaka, and N. Ogata, J. Phys. Chem., 99, 12294 (1995).

17. T. Saito, N. Kurosawa, and M. Watanabe, Kobunshi Ronbunshu, $\mathbf{5 5}$ 200 (1998).

18. F. S. Arimoto and A. C. Haven Jr., J. Am. Chem. Soc., 77, 6295 (1955).

19. M. D. Rausch and A. Siegel, J. Organometal. Chem., 11, 317 (1968).

20. T. Kelen and F. Tüdôs, J. Macromol. Sci., A9, 1 (1975).

21. J. R. MacCallum, "Polymer Electrolyte Reviews 1 and 2", C. A. Vincent, Ed., Elsevier, London, 1987 and 1989.

22. M. Watanabe, M. L. Longmire, and R. W. Murray, J. Phys. Chem., 94, $2614(1990)$

23. M. Watanabe, T. T. Wooster, and R. W. Murray, J. Phys. Chem., 95, $4573(1991)$

24. J. F. Castner and L. B. Wingber Jr., Biochemistry, 23, 2203 (1984).

25. H. Nagasaka, T. Saito, H. Hatakeyama, and M. Watanabe, Denki Kagaku, 63, 1088 (1995).

26. T. Saito and M. Watanabe, React. and Func. Polym. 37, 263 (1998). 